Article

\title{
Evaluation of the SOA Formation in the Reaction of Furfural with Atmospheric Oxidants
}

\author{
Inmaculada Colmenar ${ }^{1,2}$, Pilar Martín ${ }^{1,2}$, Beatriz Cabañas ${ }^{1,2, *}$, Sagrario Salgado ${ }^{1,2}$, \\ Florentina Villanueva ${ }^{2}$ and Bernabe Ballesteros ${ }^{1,2}$ \\ 1 Department of Physical Chemistry, Faculty of Chemical Sciences and Technologies, University of Castilla-La \\ Mancha (UCLM), Avda. Camilo José Cela S/N, 13071 Ciudad Real, Spain; inmacolmenar@yahoo.es (I.C.); \\ Mariapilar.martin@uclm.es (P.M.); sagrario.salgado@uclm.es (S.S.); bernabe.ballesteros@uclm.es (B.B.) \\ 2 Research Institute on Combustion and Atmospheric Pollution (ICCA), University of Castilla-La Mancha, \\ Camino Moledores S/N, 13071 Ciudad Real, Spain; florentina.vgarcia@uclm.es \\ * Correspondence: beatriz.cabanas@uclm.es
}

Received: 28 July 2020; Accepted: 27 August 2020; Published: 30 August 2020

check for updates

\begin{abstract}
An experimental product study of the reactions of furfural with the main tropospheric oxidants $\left(\mathrm{Cl}, \mathrm{OH}\right.$ and $\left.\mathrm{NO}_{3}\right)$ has been carried out using a Fourier Transform Infrared spectrophotometer (FTIR) and a gas chromatograph-mass spectrometer with a time of flight detector (GC-TOFMS). The main gas-phase products detected were 5-chloro-2 $(5 H)$-furanone, maleic anhydride, 2-nitrofuran and CO. Molar yields were quantified for the detected products in these reactions, thus suggesting the existence of nongaseous products that could not be observed with the analytical techniques employed. The formation of Secondary Organic Aerosol (SOA) from the oxidation of furfural with $\mathrm{Cl}$ atoms, $\mathrm{OH}, \mathrm{NO}_{3}$ and ozone was investigated in a smog chamber in the absence of inorganic seed aerosols. The experimental results show the formation of ultrafine particles (less than $1 \mu \mathrm{m}$ in diameter) for all of the studied reactions except for the nitrate radical. Given their small size, these ultrafine particles $(<1 \mu \mathrm{m})$ can easily penetrate into the respiratory tract and reach the alveolar region. These particles, therefore, have the potential to cause severe damage to the respiratory system. The aerosol yield obtained, Y, was low $(<0.04)$ in all cases, which means that the aerosols generated from furfural, under atmospheric conditions, could have little impact.
\end{abstract}

Keywords: furfural; atmospheric degradation; aerosol; reaction products; mechanism

\section{Introduction}

Furfural (2-furanaldehyde) is known to be present in the atmosphere as a reaction product of alkylfurans with different tropospheric oxidants [1] and as a biomass combustion product [2]. The main sink for furfural in the troposphere is the reaction with the hydroxyl radical $(\mathrm{OH})$ during daytime [3] and with the nitrate radical $\left(\mathrm{NO}_{3}\right)$ at night [4]. This compound could also be an important ozone generator in the troposphere due to its high estimated Maximum Incremental Reactivity (MIR) values (22.4 $\left.\mathrm{gO}_{3} / \mathrm{g} \mathrm{COV}\right)$ [3]. The reactivity of furfural with chlorine and bromine atoms has previously been studied by Cabañas et al. [5] and Bierbach et al. [6], respectively. Furthermore, the photochemistry of furfural has been studied by Hiraoka and Srinivasan [7] and Gandini et al. [8]. Furfural can react with tropospheric oxidants by hydrogen abstraction from the carbonyl group, by electrophilic addition to the double bond of the aromatic ring or by a combination of these two mechanisms. Recent theoretical studies carried out by Huang et al. [9] and Zhao and Wang [10] suggested that furfural reacts with $\mathrm{OH}$ and $\mathrm{NO}_{3}$ radicals mainly by $\mathrm{C} 5$ addition ( $\left.\sim 59 \%\right)$. For C2 addition, calculations suggest a $\sim 40 \%$ contribution. Hydrogen abstraction seems to make a minor contribution only $(\sim 0.05 \%$ for nitrate 
radicals and $2.8 \%$ for $\mathrm{OH})[9,10]$. To date, experimental studies on furfural reaction products have not been reported in the literature.

Aerosols play an important role in numerous environmental processes. Aerosols can absorb and scatter solar and Earth radiation, influence the generation of clouds and heterogeneous reactions in the atmosphere and thus affect the abundance and distribution of trace gases in it [11,12]. As a result of these interactions, aerosols influence the Earth's radiation balance, thus playing an important role in climate. It is believed that certain types of organic volatile or semivolatile compounds like cycloalkenes, aromatic hydrocarbons and terpenes favor the generation of Secondary Organic Aerosol (SOA). Moreover, interest in studying heterogeneous reactions involving carbonyl compounds has increased in recent years because of their high SOA-forming potential [13]. Therefore, it is believed that furfural could be a potential aerosol-former because it has two main features for generating SOA: a cyclic aromatic structure and a carbonyl group.

A product study of the gas-phase reactions of furfural with chlorine atoms and hydroxyl and nitrate radicals has been carried out in this work in order to determine the main reaction pathways. SOA formation for the reaction of furfural with $\mathrm{Cl}, \mathrm{OH}$ and $\mathrm{O}_{3}$ was also investigated using a smog chamber. Data were analyzed using a Fast Mobility Particle Sizer Spectrometer (FMPS) for SOA experiments and a Fourier Transform Infrared spectrophotometer (FTIR) and a gas chromatograph-mass spectrometer with a time of flight detector (GC-TOFMS) for the product study in gas-phase.

\section{Experimental}

\subsection{Materials}

The chemicals were obtained commercially: furfural (Aldrich, St. Louis, MO, USA, 99\%), 2-nitrofuran (Aldrich, 99\%), maleic anhydride (Aldrich, 99\%), nitric acid (65\%, Fluka), hydrochloric acid (37\%, Fluka), 2-(5H)-furanone (98\%, Aldrich), CO (99.998\%, Praxair, Danbury, CT, USA), $\mathrm{Cl}_{2}$ (Praxair, $>99.8 \%$ ), air (Praxair, 99.999\%) and NO (Praxair, 99\%). OH radicals were synthesized by continuous photolysis of $\mathrm{CH}_{3} \mathrm{ONO}$ in the presence of $\mathrm{NO}$ in air at a wavelength of $360 \mathrm{~nm}$. $\mathrm{CH}_{3} \mathrm{ONO}$ was generated in the laboratory as described elsewhere [14]. $\mathrm{NO}_{3}$ radicals were obtained by thermal decomposition of $\mathrm{N}_{2} \mathrm{O}_{5}$, which was synthesized in the laboratory [15]. Ozone was obtained from an ozonizer (OG Ozogas model TRCE-5000, ORSIS, Moscow, Russia) with a maximum production rate of $5 \mathrm{~g} \mathrm{O}_{3} / \mathrm{h}$.

\subsection{Methods}

\subsubsection{Gas-Phase Product Study}

The experimental system used in this study has been described in previous works $[4,16]$ and thus it will be only briefly described here. Product experiments were carried out at room temperature ( $297 \pm 2 \mathrm{~K})$ and atmospheric pressure (700 \pm 1 Torr) with synthetic air in two different reaction chambers: (1) a 50 L Pyrex ${ }^{\circledR}$ glass cell with in situ FTIR equipment (Nicolet 6700, Thermo Fisher Scientific, Waltham, MA, USA) equipped with six actinic fluorescent lamps $\left(\lambda_{\max }=360 \mathrm{~nm}\right),(2)$ Teflon ${ }^{\circledR}$ (Wilmington, DE, USA) reactor of 150 or $500 \mathrm{~L}$, the latter was employed for the study with the nitrate radical. These Teflon ${ }^{\circledR}$ reactors were surrounded by UV-Vis lamps and equipped with ports for sampling onto a 30/50 $\mu \mathrm{m}$ solid-phase microextraction (SPME) fiber of divinylbenzene/carboxen/polydimethylsiloxane (DVB/CAR/PDMS). The fiber was exposed in the reactor during $60 \mathrm{~s}$ and then thermally desorbed during $15 \mathrm{~min}$ at $250^{\circ} \mathrm{C}$ in the injection port of the gas chromatograph. The compounds were separated by a capillary column $(30 \mathrm{~m} \times 0.3 \mathrm{~mm} \times 1 \mu \mathrm{m}$, Tracsil TRB-1701 Teknokroma, Barcelona, Spain). Detection was performed by mass spectrometry in electron ionization mode (EI) with a time of flight analyzer, GC-TOFMS (AccuTOF GCv Jeol, Tokyo, Japan). For the study of each reaction at least 2 sets of experiments were performed following the reaction at about $45 \mathrm{~min}$.

For GC-TOFMS analysis, products were identified according to their retention time and/or by comparison of their mass spectra with the database. In the quantitative product analysis previous 
calibrations were carried out by introducing a known concentration of a commercial sample into the reactor (S1: Annex I in Supplementary Materials). For FTIR analysis, a spectral subtraction procedure was used to obtain the concentrations of furfural and products as a function of the reaction time. Identification was carried out by comparing reaction samples with calibrated reference IR spectra. Quantification of species was carried out by calibrated reference procedure (S2: Annex II in Supplementary Materials). For each experiment, over 30-45 spectra were recorded with a spectral resolution of $1 \mathrm{~cm}^{-1}$.

The initial concentrations of reactants in this set of experiments were as follows: (in parts per million, ppm): furfural, 10-40 for FTIR and 2-8 for GC-TOFMS; $\mathrm{Cl}_{2}, 20$ for FTIR and 2-7 for GC-TOFMS; $\mathrm{CH}_{3} \mathrm{ONO}$ and NO 7-10 for FTIR and 3-5 for GC-TOFMS; $\mathrm{N}_{2} \mathrm{O}_{5}, 10$ for FTIR and 20 for GC-TOFMS experiments.

\subsubsection{SOA Formation Study}

Experiments were carried out in the $500 \mathrm{~L} \mathrm{Teflon}{ }^{\circledR}$ reactor mentioned above. Experiments were performed at room temperature and atmospheric pressure. An FMPS 3091, TSI equipment was employed to obtain the size distribution. The decay of furfural was monitored by GC-TOFMS, following the same procedure described for the study of gas-phase products. The aerosol mass concentration, $\mathrm{M}_{0}$, was calculated by FMPS from the mobility diameters determined by this instrument on assuming spherical shape and a density of the aerosol of $1 \mathrm{~g} \mathrm{~cm}^{-3}$.

\section{Results and Discussion}

\subsection{Gas-Phase Products}

In order to facilitate the identification of the generated products, a general mechanism has been proposed for hydrogen abstraction and double bond addition. The presence of the - $\mathrm{CHO}$ group in $\mathrm{C} 2$ leads to the deactivation of the $\mathrm{C} 3$ and $\mathrm{C} 5$ positions of the aromatic ring due to its negative inductive effect. However, according to the number of resonance forms generated by the attack of the oxidant $\mathrm{X}$ $\left(\mathrm{Cl}, \mathrm{OH}\right.$ or $\mathrm{NO}_{3}$; Scheme $\mathrm{S} 1$, Supplementary Materials), the most favored positions seem to be $\mathrm{C} 2$ and $\mathrm{C} 5$. This assumption was confirmed by theoretical calculations $[9,10]$. Of these two positions, C2 and C5, the first is hindered due to the presence of the carbonyl group in the same position. As a consequence, it is expected that the $\mathrm{C} 5$ attack will be preferred. Similar double bond addition mechanisms have been proposed for the reactivity of alkylfurans [1,17]. Moreover, the furfural can react by aldehydic hydrogen abstraction but, according to the bibliographic data, the abstraction of hydrogen from the aromatic ring is less likely [18]. This behavior has also been described in previous theoretical works regarding the reactivity of furfural with $\mathrm{OH}[10]$ and $\mathrm{NO}_{3}$ [9]. According to these works, a similar reaction mechanism for the reactions with chlorine atoms has been proposed (see Scheme 1).

The formation of maleic anhydride (P2) and 5-chloro-2-(5H)-furanone (P1) as reaction products was evidenced by GC-TOFMS. The presence of maleic anhydride was confirmed by comparing the retention time and mass spectrum with those of the commercial compound. Furthermore, 5-chloro-2-(5H)-furanone is not commercially available so its formation was confirmed by comparison with the EI mass spectrum obtained in previous works [17]. The formation of this compound was also observed in the experiments performed by FTIR spectroscopy. An example of the IR bands due to the reaction products generated in the reaction of furfural with $\mathrm{Cl}$ atoms is shown in Figure 1.

The bands centered at 2890, 2351 and $2100 \mathrm{~cm}^{-1}$ (Figure $1 \mathrm{~b}$ ) are assigned to $\mathrm{HCl}, \mathrm{CO}_{2}$ and $\mathrm{CO}$, respectively. $\mathrm{CO}$ may be generated by the decarboxylation of the $\mathrm{CHO}$ group and $\mathrm{HCl}$ is a coproduct of the hydrogen abstraction process. However, the concentrations of these compounds must be treated with caution since they are also present in the chamber when air and $\mathrm{Cl}_{2}$ are exposed to visible light. The absorption band at $1829 \mathrm{~cm}^{-1}$ is assigned to 5-chloro-2-(5H)-furanone, which has been proposed as a product from the $\mathrm{C} 5$ addition. This type of furanone has also been detected in previous works as a product of the reaction of alkylfurans with $\mathrm{Cl}$ atoms [17]. There is a very good agreement 
between the residual product spectrum and the bibliographic spectra of 5-chloro-2(5H)-furanone [17] (Figure 1d), which strongly supports the finding that the residual FTIR features are mainly attributable to 5-chloro-2(5H)-furanone.

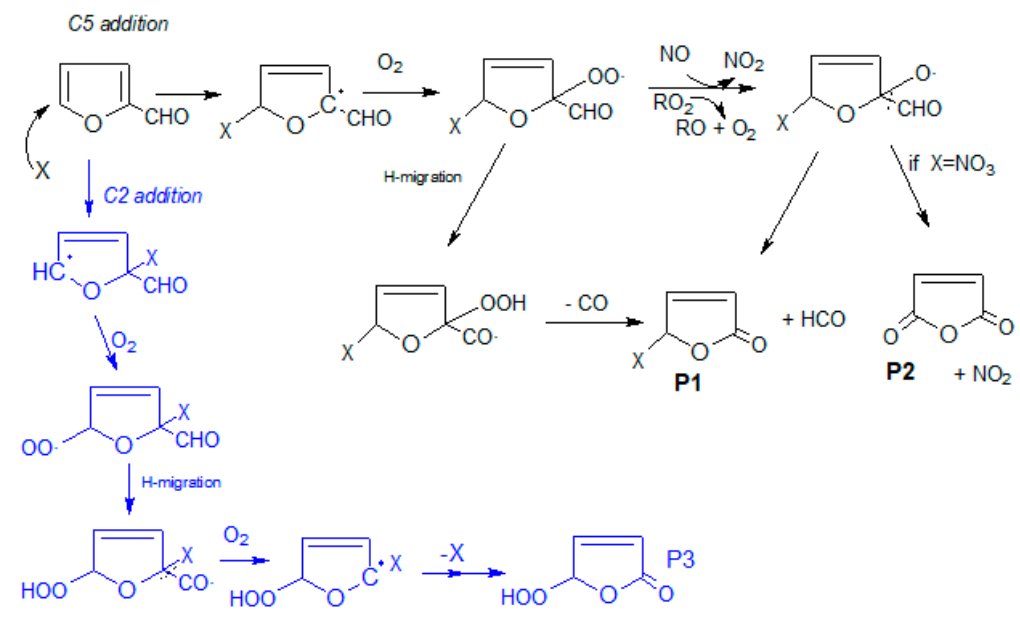

Scheme 1. General $\mathrm{C} 5$ addition mechanism in the reaction of furfural with atmospheric oxidants $X$ ( $\mathrm{Cl}$ atoms, $\mathrm{OH}$ or $\mathrm{NO}_{3}$ radicals). The secondary route for $\mathrm{C} 2$ addition is shown in blue. Confirmed products are shown in bold.

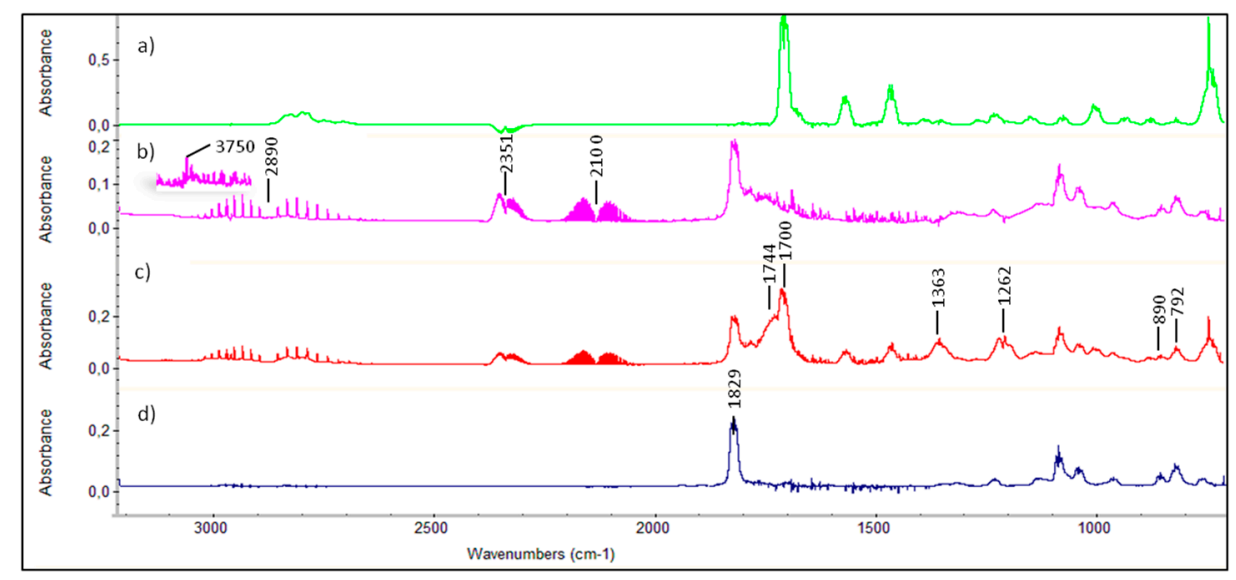

Figure 1. (a) FTIR spectra of furfural. (b) Furfural with chlorine atoms after 30 min of reaction. (c) furfural with chlorine atoms in the presence of $\mathrm{NO}$ after $20 \mathrm{~min}$ of reaction. (d) 5-chloro-2-(5H)-furanone.

In the residual product spectrum, the formation of maleic anhydride was not observed, possibly due to overlap with the chlorofuranone bands (Supplementary Materials Figure S2). However, the formation of a broad band at around $1797-1760 \mathrm{~cm}^{-1}$ suggests the presence of one or more compounds with a lactone-like structure. This fact, along with the band observed at $3750 \mathrm{~cm}^{-1}(v \mathrm{O}-\mathrm{H})$, could indicate the formation of 5-hydroperoxy-2(5H)-furanone (P3), which could be generated from the chlorine addition in $\mathrm{C} 2$-as proposed in the literature for $\mathrm{NO}_{3}$ [9] and $\mathrm{OH}$ [10] radicals (blue route in Scheme 1). In the latter case, ring-opening products have also been theoretically proposed in the literature, although this route is only expected to be minor. Moreover, maleic anhydride, which was detected in our experiments, can also be formed in the $\mathrm{H}$ abstraction route (Scheme 2), albeit to a lesser extent.

Product formation for the reaction of furfural with chlorine atoms in the presence of NO was also studied. Two analogous mechanisms have been proposed by considering the reaction with NOx. The same products were detected as in the absence of NOx. Besides, the presence of NOx leads to the formation of nitrate and peroxyacylnitrate products. 


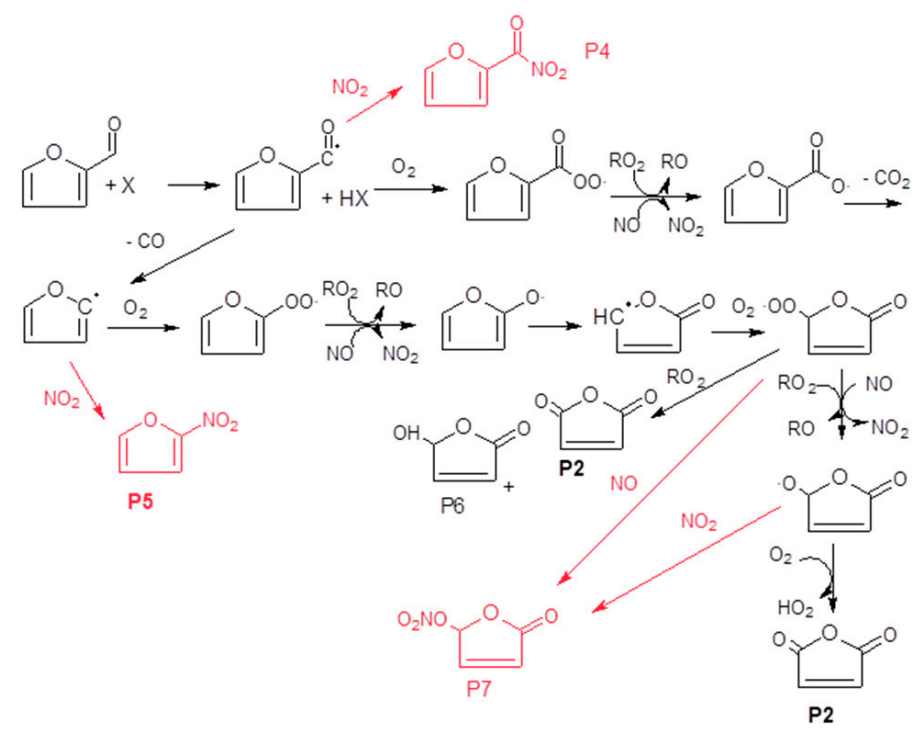

Scheme 2. General hydrogen abstraction mechanism in the reaction of furfural with atmospheric oxidants $\mathrm{X}\left(\mathrm{Cl}\right.$ atoms, $\mathrm{OH}$ or $\mathrm{NO}_{3}$ radicals). The proposed route for the reaction in the presence of $\mathrm{NOx}$ is shown in red.

The formation of 5-chloro-2 $(5 H)$-furanone is evidenced in Figure $1 \mathrm{c}$ along with sets of IR bands at 792,1262 and $1744 \mathrm{~cm}^{-1}$ and 890,1163 and $1700 \mathrm{~cm}^{-1}$, which are absorption patterns attributed to $-\mathrm{OONO}_{2}$ and $-\mathrm{ONO}_{2}$ groups, respectively. Moreover, the band at $1798 \mathrm{~cm}^{-1}$ may be due to the presence of a substituted lactone and the band at $1843 \mathrm{~cm}^{-1}$ may be due to the presence of a carbonyl group of a nitrate compound.

For GC-TOFMS experiments, four product peaks were observed at 10.03, 12.02, 13.23 and $23.73 \mathrm{~min}$ in the gas chromatogram (see Figure 2). Peaks at 10.03 and 13.23 min were assigned to maleic anhydride and 5-chloro-2-(5H)-furanone (P1), respectively. The peak at $12.02 \mathrm{~min}$ was identified as being due to 2-nitrofuran. The assignment was confirmed by comparing the retention times and mass spectra with those of commercial samples: 2-nitrofuran and maleic anhydride. For the identification of 5-chloro-2-(5H)-furanone, the IR and MS spectra obtained for the synthesized products in our previous work were employed [17].

Matches were not found in the database for the peak observed at $23.73 \mathrm{~min}$, but according to the FTIR data, one would expect the formation of a nitrate compound containing a carbonyl group. Therefore, taking in account the FTIR data, the $m / z$ value (141) and pattern observed (Figure S2), this peak is tentatively assigned to 4-nitrooxidanyl- $\gamma$-crotonlactone (P4, Scheme 2$)$. However, the presence of this product was not confirmed because it is not commercially available.

The formation of 2-furylnitroketone and 2-nitrofuran (P5) can be explained by the reaction between the intermediate radicals generated and $\mathrm{NO}_{2}$, which is present in the $\mathrm{NOx}$ mixture (red route in Scheme 2). These radicals react slowly with $\mathrm{O}_{2}$ since it is a slightly exothermic and highly reversible reaction, but, alternatively, they would react with other species such as $\mathrm{O}_{3}, \mathrm{NO}_{2}$ and $\mathrm{RO}_{2}$ [10].

Analogous mechanisms were proposed for the reaction of furfural with $\mathrm{OH}$ radicals. According to the literature, 2-oxo-3-pentene-1,5-dialdehyde, 5-hydroxy-2-(5H)-furanone, 4-oxo-2-butenoic acid and maleic anhydride are the main products expected for the $\mathrm{OH}$ oxidation of furfural [10]. From this list of proposed products, only the formation of maleic anhydride was observed in our experiments by GC-TOFMS. The FTIR spectra are in this case more difficult to analyze due to the overlap of the $\mathrm{OH}$ precursors employed $\left(\mathrm{CH}_{3} \mathrm{ONO}+\mathrm{NO}\right)$ and the decomposition products (formaldehyde, $\mathrm{CO}$ and $\mathrm{NO}_{2}$ ). However, the IR bands observed in the product spectra after $30 \mathrm{~min}$ of photolysis (see Figure S3, Supplementary Materials) have been associated with the presence of $-\mathrm{ONO}_{2}$ and $-\mathrm{OONO}_{2}$ groups, as described previously. These bands may correspond to the products $\mathrm{P} 4$ and P5, which may be formed when certain levels of NOx are present in the gas mixture. 


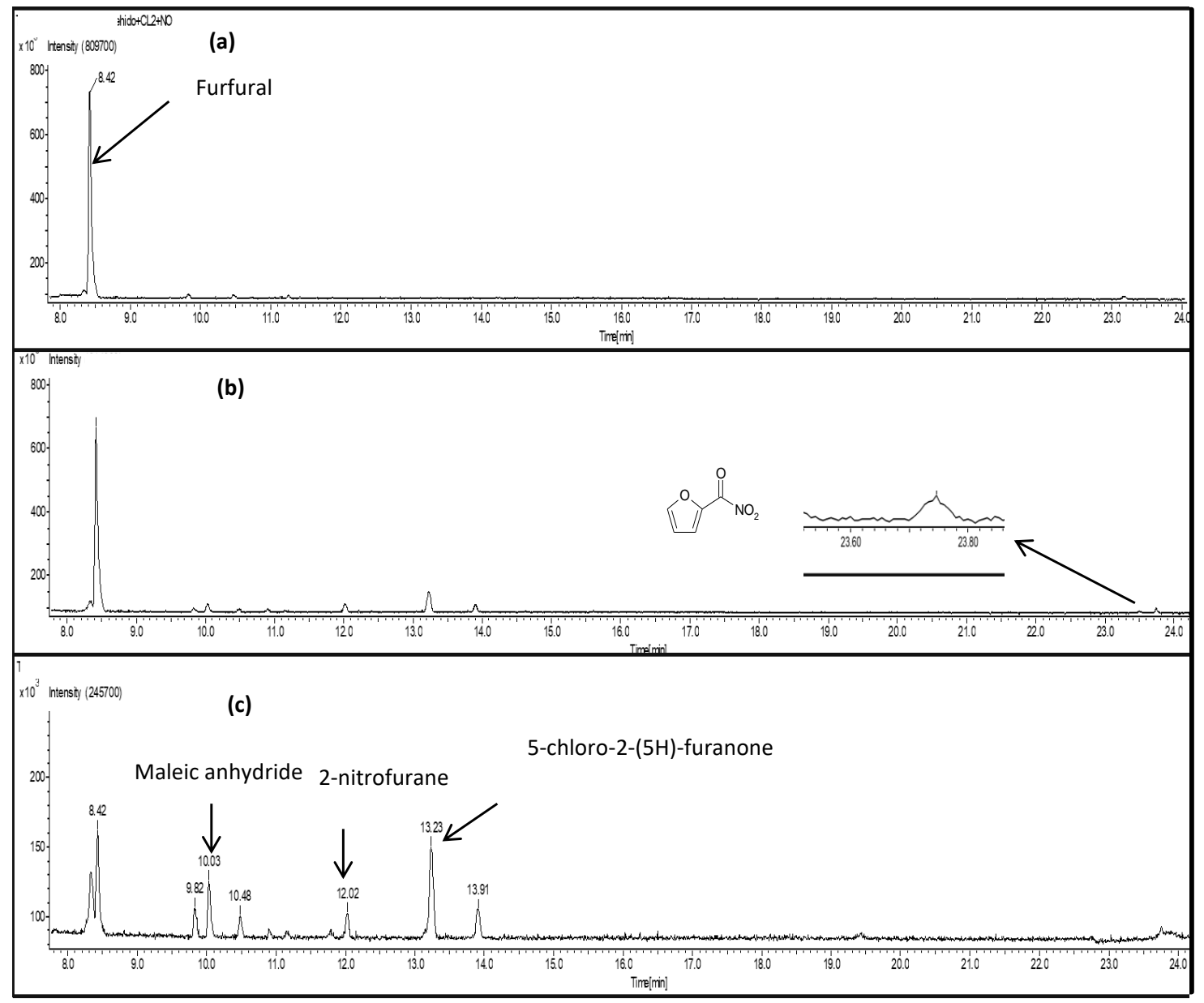

Figure 2. Gas chromatograms obtained for the reaction of furfural with chlorine atoms in the presence of $\mathrm{NO}$ at different times: $\mathrm{t}=0 \mathrm{~min}(\mathbf{a}), \mathrm{t}=5 \mathrm{~min}(\mathbf{b})$ and $\mathrm{t}=10 \mathrm{~min}(\mathbf{c})$.

In the case of the reaction of furfural with $\mathrm{NO}_{3}$, the precursor employed $\left(\mathrm{N}_{2} \mathrm{O}_{5}\right)$ decomposes into $\mathrm{NO}_{2}$ and nitric acid $\left(\mathrm{HNO}_{3}\right)$. Assuming a reaction mechanism similar to that proposed for the reaction with chlorine atoms and $\mathrm{OH}$ radicals, one would expect the formation of the addition product 5-nitrate-2-(5H)-furanone (P1), maleic anhydride (P2) and other nitrate products.

In GC-TOFMS experiments, similar results were obtained as in the case of the reaction with chlorine atoms in the presence of NOx. Three products were identified by gas chromatography after $3.5 \mathrm{~h}$ of reaction: maleic anhydride, 2-nitrofuran and 2-furylnitroketone (not confirmed).

For FTIR experiments, after 60 min of reaction, the typical IR bands of $-\mathrm{ONO}_{2}(852,1288$ and $\left.1666 \mathrm{~cm}^{-1}\right)$ and $-\mathrm{OONO}_{2}\left(792,1030\right.$ and $\left.1726 \mathrm{~cm}^{-1}\right)$ groups were observed (Figure S4, Supplementary Materials). Once again, the band at $1805 \mathrm{~cm}^{-1}$ can be assigned to the presence of a substituted lactone (in this case 5-hydroxy-2(5H)-furanone (P6), maleic anhydride (P2), or 5-nitrate-2-(5H)-furanone (P1)). The band at $1840 \mathrm{~cm}^{-1}$ may be due to the presence of another $\mathrm{C}=\mathrm{O}$ group of a nitrate compound, which could be assigned to the formation of 2-furylcetone mentioned above.

The formation of 5-nitrate-2-(5H)-furanone and maleic anhydride have also been suggested in the literature [9]. The IR absorption bands observed are also consistent with the formation of 5-hydroperoxy-2-(5H)-furanone and 3-nitrate-2-hydroperoxy-3(2H)-furanone, which were theoretically proposed in work by Huang et al. [9]. Once again, the presence of these products was not confirmed because they are not commercially available. 
The quantification of the identified products was only possible in certain cases. The product concentrations were estimated using calibration curves obtained previously by introducing into the reactor a set of samples of known concentration.

For some products, such as 5-chloro-2 $(5 \mathrm{H})$-furanone and $\mathrm{NO}_{2}$, the concentration profiles were obtained using IR absorption cross-sections found in the literature [19]. In the case of 5-chloro-2-(5H)-furanone, the concentration was estimated using the IR absorption coefficient of the 2-(5H)-furanone [19] because of their structural similarity and since the former is not commercially available. A value for this coefficient of $(1.65 \pm 0.27) \times 10^{-3} \mathrm{ppm} \mathrm{V}^{-1} \mathrm{~m}^{-1}$ for the band of $1811 \mathrm{~cm}^{-1}$ was used. For $\mathrm{NO}_{2}$, a value of $(1.46 \pm 0.04) \times 10^{-3} \mathrm{ppm} \mathrm{V}^{-1} \mathrm{~m}^{-1}$ for the band at $1630 \mathrm{~cm}^{-1}$ was taken for the quantitative analysis. In addition to these two products, the concentrations of maleic anhydride, $\mathrm{CO}, \mathrm{HCl}, \mathrm{HNO}_{3}$ and 2-nitrofuran were obtained. An example of the concentration-time profiles for the reaction of $\mathrm{Cl}$ atoms and furfural is shown in Figure 3.

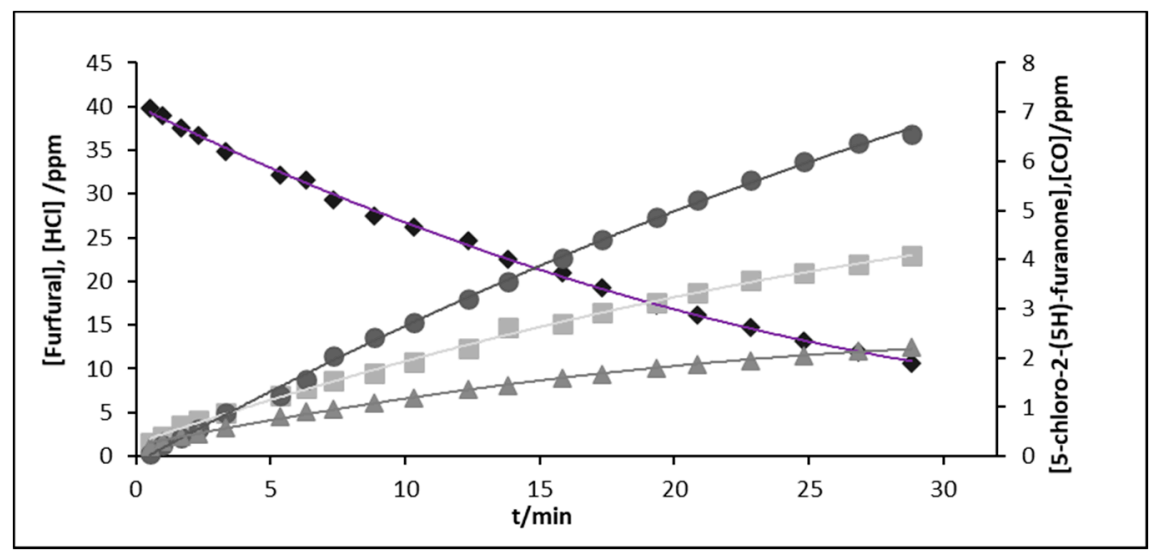

Figure 3. FTIR concentration-time profiles for the reaction of furfural with chlorine atoms. Furfural,

- $\mathrm{HCl}, \bullet \mathrm{CO}, \boldsymbol{\Delta}$ 5-chloro-2-(5H)-furanone.

The profiles are typical of primary products that undergo a progressive increase in the concentration from the early stages of the reaction. Similar time-concentration profiles were obtained for 5-chloro-2-(5H)-furanone, $\mathrm{CO}$ and $\mathrm{HCl}$ in the case of the reaction of furfural with chlorine atoms in the presence of NOx. In the cases of maleic anhydride and 2-nitrofuran, the curves obtained after 4-6 min of reaction and using GC-MS/TOF suggest the loss of these products through secondary reactions (Figure S5, Supplementary Materials). As mentioned before, chlorofuranone has a typical primary product profile while the nitro-2-furylketone (P7) has a secondary product profile (Figure S6, Supplementary Materials). This may indicate that high levels of $\mathrm{NO}_{2}$ are required for the generation of this product (P7).

The yields of the primary products were obtained from the slopes of plots of the amounts of reaction product formed versus the amounts of consumed furfural. The product yields obtained for the reaction of furfural with different oxidants are provided in Table 1. 
Table 1. Product yields confirmed by FTIR and GC-TOFMS analysis for the reaction of furfural with different oxidants.

\begin{tabular}{ccccc}
\hline Compound & \multicolumn{5}{c}{ Molar Yield (\%) } \\
$\mathrm{HCl}$ & $\mathrm{Cl}$ & $\mathrm{Cl}+\mathrm{NOx}$ & $\mathrm{OH}$ & $\mathrm{NO}_{3}$ \\
$\mathrm{CO}$ & $(72.9 \pm 0.9)^{\mathrm{a}}$ & $(56.6 \pm 2.1)^{\mathrm{a}}$ & - & - \\
5-chloro-2-(5H)-furanone & $(22.9 \pm 0.4)^{\mathrm{a}}$ & $(11.4 \pm 0.4)^{\mathrm{a}}$ & $(23.8 \pm 0.3)^{\mathrm{a}}$ & - \\
Maleic anhydride & $(6.8 \pm 0.1)^{\mathrm{a}}$ & $(6.0 \pm 0.2)^{\mathrm{a}}$ & - & $(20.0 \pm 3.0)^{\mathrm{b}}$ \\
2-nitrofuran & $(6.1 \pm 0.5)^{\mathrm{b}}$ & $(6.7 \pm 0.2)^{\mathrm{b}}$ & $(8.8 \pm 0.6)^{\mathrm{b}}$ & $(58.6 \pm 8.6)^{\mathrm{b}}$ \\
5-hydroxy-2(5H)-furanone & & $(10.8 \pm 0.5)^{\mathrm{b}}$ & - & \\
(P6) & & $\mathrm{X}^{\mathrm{a}}$ & $\mathrm{X}^{\mathrm{a}}$ & \\
4-nitrooxindanyl- $\gamma$-crotonlactone & & $\mathrm{X}^{\mathrm{a}}$ & & \\
(P4) & & $\mathrm{X}^{\mathrm{a}}$ & \\
nitro-2-furylketone (P7) & &
\end{tabular}

Products identified by ${ }^{a}$ FTIR and ${ }^{\mathrm{b}}$ GC-TOFMS; Unconfirmed X. The yield error is 2 times the standard deviation calculated from the least-square fit.

For the reactions of furfural with chlorine atoms in the absence and presence of NOx, the molar yields obtained for 5-chloro-2-(5H)-furanone were similar for both reactions, although the levels of $\mathrm{HCl}$ and $\mathrm{CO}$ quantified were lower for the reaction in the presence of NOx. Yields of $\mathrm{HCl}$ and $\mathrm{CO}$ are overestimated due to wall secondary reactions and traces of humidity.

For the reaction of furfural with the $\mathrm{OH}$ radical, only the levels of $\mathrm{CO}$ (using FTIR) and maleic anhydride (using GC-MS/TOF) were confirmed. Both products lead to primary concentration-time profiles, as in the case of chlorine reactions. In this case, the yield obtained for the anhydride was slightly higher than that obtained for the reaction with chlorine atoms.

For the reaction with $\mathrm{NO}_{3}$ radicals, only the levels of $\mathrm{NO}_{2}, \mathrm{CO}$ and $\mathrm{HNO}_{3}$ were confirmed by FTIR analysis. A progressive increase in the concentration of $\mathrm{NO}_{2}$ during the reaction can be seen (Figure S7 Supplementary Materials), but this began to decay over time as a result of secondary reactions. The high concentrations detected initially are attributable to the thermal decomposition of the precursor $\left(\mathrm{N}_{2} \mathrm{O}_{5}\right)$. The yield was estimated to be $(78.3 \pm 6.6) \%$. In this case, the high levels of $\mathrm{NO}_{2}$ detected could be of great importance since it can react with the reaction intermediates generated. The concentration profiles for $\mathrm{CO}$ and $\mathrm{HNO}_{3}$ are more or less constant, with a slight decay observed for the latter throughout the reaction. This trend can be attributed to the deposition of nitric acid on the reactor walls. However, $\mathrm{HNO}_{3}$ levels are difficult to evaluate since, as mentioned before, they are strongly influenced by the existence of secondary reactions. Molar yields of $(58.6 \pm 8.6) \%$ and $(20 \pm 3) \%$ for 2-nitrofuran and maleic anhydride, respectively, were quantified by GC-TOFMS. As can be seen from the results in Table 1, this yield is considerably higher than in the case of the other oxidants, which suggests in this case an extra route for the generation of maleic anhydride (Scheme 1). As mentioned above, the curve contours observed for maleic anhydride after $2 \mathrm{~h}$ of reaction suggest loss due to secondary reactions. The molar yield for the 2-furylnitroketone could not be obtained since it is not commercially available.

The studied oxidants led to the formation of the common product maleic anhydride. This compound may be generated by hydrogen abstraction of the - $\mathrm{CHO}$ group (via I), since the formation of its coproduct (5-hydroxy-2-(5H)-furanone) via II has not been confirmed. For reactions with chlorine atoms and the $\mathrm{OH}$ radical, the yield for maleic anhydride obtained is between 6 and $9 \%$. However, this yield is underestimated because it is suspected that this compound undergoes a photolysis process [20]. However, in the case of the nitrate radical, as mentioned above, the anhydride has an extra contribution by the additional pathway. Its yield $(\sim 20 \%)$ is approximately $2-3$ times greater than for other reactions. The results obtained in this study confirm that for reactions with chlorine atoms and the $\mathrm{OH}$ and $\mathrm{NO}_{3}$ radicals, furfural reacts by both mechanisms, namely $\mathrm{C} 5$ addition and aldehydic hydrogen abstraction. According to the estimated yield for 2-nitrofuran, it is believed that the abstraction process occurs to a greater extent for nitrate radicals. The reaction with $\mathrm{NO}_{3}$ radicals led to the formation of various nitrated products such as 2-nitrofuran (P5) and unconfirmed products 
such nitro-2-furylketone (P4), which are common products to those obtained in the reaction with chlorine atoms in the presence of NOx. This may be due to high levels of $\mathrm{NO}_{2}$, which make furfural react by following a parallel path (marked in red in the proposed reaction mechanism). This behavior was not observed with the $\mathrm{OH}$ radical, where the concentrations of $\mathrm{NO}_{2}$ due to the decomposition of methylnitrite employed as the precursor is lower.

\subsection{SOA Size Distributions}

The few products identified in the gas-phase study and their low yields lead us to believe that some of the reaction products generated are not being observed in the gas-phase. This may be because many of the furfural reaction products are in a condensed phase, and therefore, they are not being correctly sampled. For this purpose, a series of experiments was performed under atmospheric pressure and room temperature (similar experimental conditions to those used in the products' experiments) to study the formation of aerosols in the reaction of furfural with $\mathrm{Cl}, \mathrm{OH}$ and $\mathrm{O}_{3}$. The same set of experiments was performed to study the reaction with $\mathrm{NO}_{3}$, but particle formation was not observed.

The decay of furfural versus the variation of SOA mass $\left(\mathrm{M}_{0}\right)$ for the reaction with chlorine atoms is represented in Figure 4. The steady state for aerosol production was observed after $30 \mathrm{~min}$, with a maximum mass of around $9 \times 10^{2} \mu \mathrm{g} \mathrm{m}^{-3}$ for the reaction with chlorine atoms. A typical concentration profile, as described in the literature [21], was observed in this experiment, thus suggesting a strong relationship between the concentration of furfural and aerosol generation.

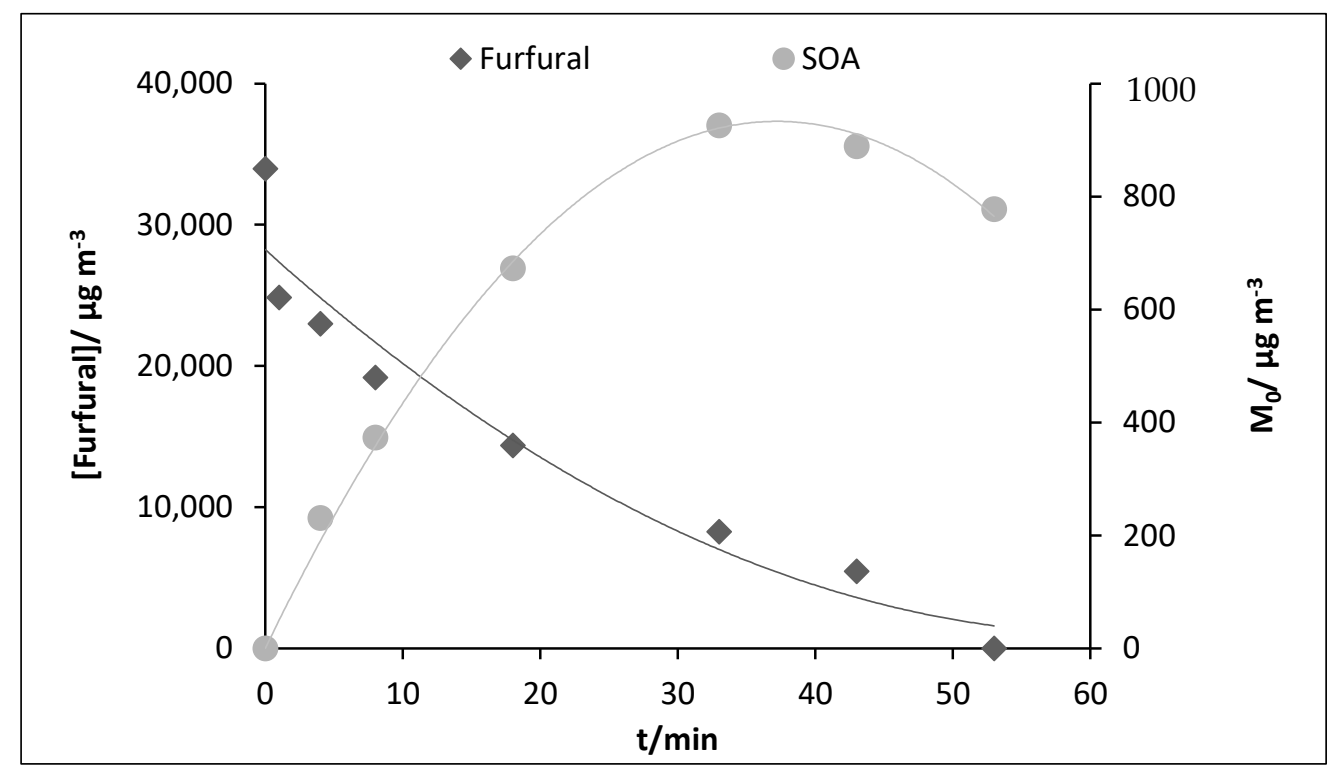

Figure 4. Profile of furfural and aerosol mass under chlorine degradation conditions.

As SOA wall loss was observed, the aerosol mass concentration $\left(\mathrm{M}_{0}\right)$ was corrected by using the wall deposition coefficient rate obtained in this work $\left(k w=(2.95 \pm 0.46) \times 10^{-5} \mathrm{~s}^{-1}\right)$.

A significant amount of particulate matter, i.e., between 60 and $950 \mu \mathrm{g} \mathrm{m}^{-3}$, was observed in the oxidation of furfural with chlorine atoms, $\mathrm{OH}$ radicals and ozone at the stationary state. This state is rapidly reached after $30 \mathrm{~min}$ for the chlorine and ozone reactions and after $5 \mathrm{~min}$ for the $\mathrm{OH}$ reaction. The furfural concentration was monitored by offline SPME sampling and analyzed by GC-TOFMS. The fiber was exposed in the reactor during $60 \mathrm{~s}$ and then thermally desorbed during $15 \mathrm{~min}$ at $250{ }^{\circ} \mathrm{C}$ in the injection port of the gas chromatograph. The reactor was filled with purified air, a quantity of reactant $\left(2.5-3.5 \mu \mathrm{g} \mathrm{m}^{-3}\right)$ and oxidant $\left(\sim 2.5 \times 10^{14}\right.$ molecule $\left.\mathrm{cm}^{-3}\right)$. For the study with chlorine atoms and $\mathrm{OH}$ radicals, six visible lamps were employed to start the reaction. Ozone was obtained from an ozonizer as mentioned above. Prior tests were performed to confirm the absence of particle generation from the exposure of furfural to light. 
All of the experiments were carried out in the absence of inorganic seed aerosol. The initial concentrations employed for the oxidant ([Ox.]0) and furfural or reactive organic gas ([ROG]0) are listed in Table 2 together with the reacted furfural $(\Delta[R O G])$ and aerosol yield, Y. The overall organic aerosol yield was determined by employing Equation (1):

$$
\mathrm{Y}=\frac{\mathrm{M}_{0}}{\Delta[\mathrm{ROG}]}
$$

where $\mathrm{M}_{0}$ is the organic aerosol mass concentration and $\Delta[R O G]$ is the reacted furfural, both in $\mu \mathrm{g} \mathrm{m} \mathrm{m}^{-3}$.

It can be seen from the results that atmospheric degradation of furfural leads to the formation of low vapor pressure products (particulate matter), as previously proposed in the gas-phase study.

The yield of the reaction with chlorine atoms is between 6 to 10 times greater than in the cases of ozone and $\mathrm{OH}$. The particle size obtained is also larger for the reaction with chlorine (diameters $107-523 \mathrm{~nm}$ ) and this suggests that the reaction of furfural with this oxidant leads to a more effective formation of aerosols.

Table 2. Experimental conditions employed for SOA study. Aerosol mass $\left(\mathrm{M}_{0}\right)$, aerosol yield (Y) and SOA size distribution (diameter) obtained at the end of each studied reaction.

\begin{tabular}{|c|c|c|c|c|c|c|c|}
\hline $\begin{array}{l}\text { Precursor } \\
\text { Oxidant }\end{array}$ & $\begin{array}{c}{[\text { Precursor }} \\
\text { Oxidant }]_{0} / \mathbf{1 0}^{14} \\
\text { Molecule } \mathrm{cm}^{-3}\end{array}$ & $t / \min$ & $\begin{array}{c}\Delta\left[\mathrm{ROG}_{0} / 10^{-4}\right. \\
\mu \mathrm{g} \mathrm{m} \mathrm{m}^{3}\end{array}$ & $\Delta[\mathrm{ROG}] / 10^{-4} \mu \mathrm{gm}^{3}$ & $\mathrm{M}_{0} / \mu \mathrm{g} \mathrm{m}^{3}$ & $\mathbf{Y}$ & Size/nm \\
\hline $\mathrm{Cl}_{2}$ & 2.43 & 43 & 3.4 & 2.9 & 950 & 0.03 & $107-523$ \\
\hline $\mathrm{CH}_{3} \mathrm{ONO}$ & 2.43 & 86 & 3.1 & 2.8 & 90 & 0.003 & $69-254$ \\
\hline$* \mathrm{O}_{3}$ & - & 90 & 2.5 & 1.1 & 60 & 0.005 & 39-191 \\
\hline
\end{tabular}

* $\mathrm{O}_{3}$ obtained from an ozonizer with a maximum output of $5 \mathrm{~g} \mathrm{O}_{3} / \mathrm{h}$.

In the reaction of furfural with the $\mathrm{OH}$ radical, particles were formed by irradiation of the precursor mixture $\left(\mathrm{CH}_{3} \mathrm{ONO}\right.$ and $\left.\mathrm{NO}\right)$ with visible lamps in air. The concentration and particle size observed under the same experimental conditions were lower than those obtained in the reaction with chlorine atoms. In this reaction, due to the formation of preexisting ultrafine particles from the degradation of the $\mathrm{OH}$ precursor, it is believed that these act as condensation nuclei that promote the growth of the particles in this process. However, the existence of a nucleation process cannot be dismissed.

For the study of the SOA formation in the reaction of furfural with ozone, several individual additions of a small quantity of an $\mathrm{O}_{2} / \mathrm{O}_{3}$ mixture were carried out, but only after the addition of a large excess of $\mathrm{O}_{3}$, and particle formation was observed. A similar evolution of the size distribution as in the case of chlorine atoms was observed. The SOA distribution for the reaction of furfural with chlorine atoms is shown in Figure 5. 


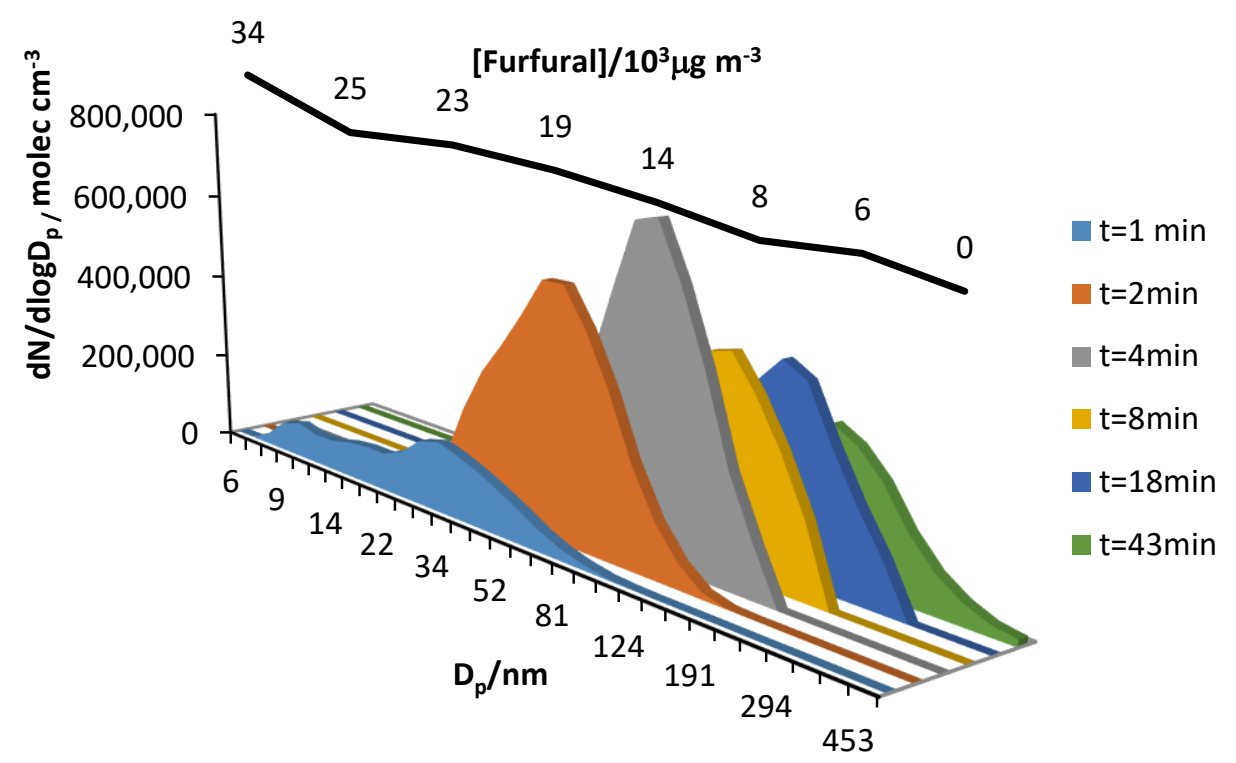

Figure 5. Size distribution of SOA particles formed in the reaction of furfural with chlorine atoms at

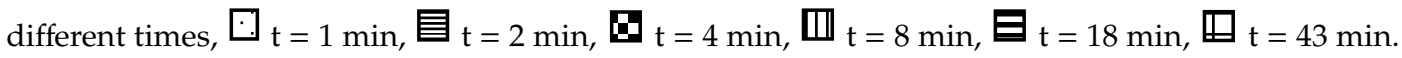
Variation of furfural concentration during the reaction. Solid line

A set of experiments at different furfural/oxidant concentrations were carried out in order to study its influence of this parameter on the aerosol yield for the reaction with chlorine atoms. The results are summarized in Table 3.

In most experiments, aerosol yields in the $5-7 \%$ range were obtained. The lowest aerosol yield was obtained in Experiment 5, in which a concentration ratio $<1$ was employed. Reaction 2, with a ratio close to one, also gave a low value of $\mathrm{Y}$.

The aerosol yields obtained in this work for the photoxidation and ozonolysis of furfural are low, but these values are of the same order of magnitude as those reported in the literature for isoprene [22,23] and pinene [24] oxidations. Nevertheless, these values may represent lower limits.

Table 3. Aerosol yield ( $\mathrm{Y}$ ) for different ratios of furfural (ROG)/ $/ \mathrm{Cl}_{2}$ concentration.

\begin{tabular}{|c|c|c|c|c|c|c|c|c|c|}
\hline Exp & {$[\mathrm{ROG}]_{0} / \mathrm{ppm}$} & {$\left[\mathrm{Cl}_{2}\right]_{0} / \mathrm{ppm}$} & {$\left[\mathrm{Cl}_{2}\right]_{0} /[\mathrm{ROG}]_{0}$} & $\% \Delta[$ ROG] & $\Delta[\mathrm{ROG}] / \mu \mathrm{gm}^{-3}$ & $\mathrm{M}_{0} / \mathrm{\mu gm}^{-3}$ & $\mathrm{C}_{\mathrm{T}} / 10^{4} \# \mathrm{~cm}^{-3}$ & $\mathbf{Y} \%$ & $t / \min$ \\
\hline 1 & 1.87 & 3.78 & 2.02 & 77 & 5658.7 & 305 & 7.39 & 5.4 & 20 \\
\hline 2 & 8.64 & 9.28 & 1.07 & 84 & 28,490 & 950 & 11.8 & 3.3 & 43 \\
\hline 3 & 9.24 & 10.83 & 1.31 & 80 & $29,040.1$ & 1773 & 13.2 & 6.1 & 53 \\
\hline 4 & 11 & 14.50 & 1.32 & 80 & $34,423.8$ & 2386 & 19 & 7 & 43 \\
\hline 5 & 13.76 & 7 & 0.50 & 63 & $34,305.9$ & 777 & 5.24 & 2.2 & 95 \\
\hline
\end{tabular}

\section{Conclusions}

The main products detected were 5-chloro-2-(5H)-furanone and maleic anhydride for the reaction with chlorine atoms. 2-nitrofuran was observed in the presence of NOx. The formation of 2-furylketone and 5-nitrate-2-(5H)-furanone has also been tentatively proposed for the reactions with nitrate radicals and chlorine atoms in the presence of NOx. A general mechanism for the atmospheric oxidation of furfural has been proposed. The attack of the oxidants occurs mainly by a double bond addition at the $\mathrm{C} 5$ position. Hydrogen abstraction is also observed for all of the studied oxidants. Furthermore, the high maleic anhydride yield obtained for nitrate reactions suggests a contribution from an extra route. When oxidation of furfural takes place under high NOx conditions, an alternative route with $\mathrm{NO} / \mathrm{NO}_{2}$ has been proposed. This behavior has been observed for nitrate and $\mathrm{Cl} / \mathrm{NOx}$ reactions.

The low yields obtained for the gas-phase products identified ( 13-23\% for chlorine and $\sim 9 \%$ for $\mathrm{OH}$ in terms of total carbon) suggest the formation of furfural products in a condensed phase. 
This statement was confirmed in our experiments, where secondary organic aerosol was observed for the reaction of furfural with chlorine atoms, $\mathrm{OH}$ radicals and ozone.

The formation of particulate matter in the reaction of furfural with chlorine atoms, $\mathrm{OH}$ radicals and ozone w observed. The aerosol yields obtained for these reactions varied in the $0.3-3 \%$ range, with the reactions with chlorine atoms giving the highest yield, $Y$. In this reaction, the influence of the oxidant/furfural ratio was studied and an average yield of $6 \%$ was obtained for most of the reactions. When $\left[\mathrm{Cl}_{2}\right] \mathrm{0} /[\mathrm{ROG}] 0$ is $\leq 1$, lower yields of around $2-3 \%$ were obtained. Although the aerosol yields obtained in this work are not particularly high, the generation of an aerosol is expected to have greater relevance in coastal areas, where the concentrations of chlorine atoms are higher and these reactions become more important. The presence of organic aerosols in the atmosphere can influence the terrestrial radiative balance since they absorb and disperse solar and terrestrial radiation and influence the generation of clouds and heterogeneous reactions [11,12]. In addition, the particulate matter observed is made up of ultrafine particles, in the order of nanometers, and they can easily penetrate the airways and reach the alveolar region. However, more experiments are required to better understand the atmospheric oxidation of furfural.

Supplementary Materials: The following are available online at http://www.mdpi.com/2073-4433/11/9/927/s1. Scheme S1: Resonance forms generated after the attack of the oxidant X. Figure S1: FTIR spectra of maleic anhydride. Figure S2: Mass spectra obtained for commercial 2-nitrofuran (a) and the products detected at 12.02 (b) and $23.73 \mathrm{~min}(\mathrm{c})$. Figure S3: IR product spectra for: furfural, with $\mathrm{OH}$ radicals at $\mathrm{t}=0$ and $\mathrm{t}=30 \mathrm{~min}$ of reaction. IR spectra of the $\mathrm{HCHO}$ detected Figure S4: IR residual products spectra after 60 min of reaction of $\mathrm{NO}_{3}$ and furfural (a) and database spectra for $\mathrm{N}_{2} \mathrm{O}_{5}$ (b) and $\mathrm{HNO}_{3}$ (c). Figure S5: Concentration-time profiles of the products observed by GC-MS/TOF for the reaction of furfural with chlorine atoms in the presence of NOx. Figure S6: Integrated peak area-time profiles of the products observed by GC-MS/TOF for the reaction of furfural with chlorine atoms in the presence of NOx. Figure S7a: Concentration-time profiles of the products observed by FTIR for the reaction of furfural with nitrate radical. Figure S7b: Concentration-time profiles of the products observed by GC-MS/TOF for the reaction of furfural with nitrate radical. S1: Annex I Calibration. Table S1: The concentration of Maleic anhydride and the calculated factors of substation. Figure S8: The factor of subtraction versus maleic anhydride concentration (ppm). Table 2: The concentration of furfural and Area of its characteristic chromatographic peak. Figure S9: Area of chromatographic peak versus furfural concentration (ppm). S2: Annex II Estimation of product yield. Figure S10: variation of concentration of $\mathrm{HCl}, \mathrm{CO}$ and 5 -chloro-2- $(5 \mathrm{H})$-furanone versus la variation of furfural for the chlorine atoms reaction.

Author Contributions: Conceptualization and supervision P.M., B.C. and S.S.; methodology, F.V. formal analysis and investigation, I.C., and B.B.; writing-original draft preparation, I.C., B.C.; writing-review and editing, B.C. All authors read and approved the final manuscript.

Funding: This research was funded by Consejería de Educación, Cultura y Deporte of Junta de Comunidades de Castilla-La Mancha and Ministerio de Ciencia Innovación y Universidades through the projects SBPLY/17/180501/000522 and RTI2018-099503-B-100, respectively, and both cofinanced by the Fondo Europeo de Desarrollo Regional (FEDER).

Conflicts of Interest: The authors declare no conflict of interest.

\section{References}

1. Villanueva, F.; Cabañas, B.; Monedero, E.; Salgado, S.; Bejan, I.G.; Martín, P. Atmospheric degradation of alkylfurans with chlorine atoms: Product and mechanistic study. Atmos. Environ. 2009, 43, 2804-2813. [CrossRef]

2. Ciccioli, P.; Brancaleoni, E.; Frattoni, M.; Cecinato, A.; Pinciarelli, L. Determination of volatile organic compounds (voc) emitted from biomass burning of mediterranean vegetation species by gc-ms. Anal. Lett. 2001, 34, 937-955. [CrossRef]

3. Colmenar, I.; Cabañas, B.; Martínez, E.; Salgado, M.S.; Martín, P. Atmospheric fate of a series of furanaldehydes by their NO3 reactions. Atmos. Environ. 2012, 54, 177-184. [CrossRef]

4. Bierbach, A.; Barnes, I.; Becker, K.H. Product and kinetic study of the OH-initiated gas-phase oxidation of furan, 2-methylfuran and furanaldehydes at $\approx 300 \mathrm{~K}$. Atmos. Environ. 1995, 29, 2651-2660. [CrossRef]

5. Cabañas, B.; Tapia, A.; Villanueva, F.; Salgado, S.; Monedero, E.; Martín, P. Kinetic study of 2-furanaldehyde, 3-furanaldehyde, and 5-methyl-2-furanaldehyde reactions initiated by $\mathrm{Cl}$ atoms. Int. J. Chem. Kinet. 2008, 40, 670-678. [CrossRef] 
6. Bierbach, A.; Barnes, I.; Becker, K.H. Rate constants of the Br-initiated gas-phase oxidation of a series of alcohols, furans and benzenes at $300 \pm 2$ K. Atmos. Environ. 1999, 33, 2981-2992. [CrossRef]

7. Hiraoka, H.; Srinivasan, R. Vapor-Phase Photochemistry of Furfural. J. Chem. Phys. 1968, 48, $2185-2189$. [CrossRef]

8. Gandini, A.; Parsons, J.M.; Back, R.A. The photochemistry of 2-furaldehyde vapour. II. Photodecomposition: Direct photolysis at 253.7 and $313 \mathrm{~nm}$ and $\mathrm{Hg}(3 \mathrm{P} 1)$-sensitized decomposition. Can. J. Chem. 1976, 54, 3095-3101. [CrossRef]

9. Huang, Z.; Zhao, N.; Ma, X.; Xu, F.; Zhang, Q.; Zhuang, T.; Wang, W. Theoretical study on the atmospheric oxidation reaction of 2-furanaldehyde initiated by $\mathrm{NO}_{3}$ radicals. Chem. Phys. Lett. 2019, 722, 50-57. [CrossRef]

10. Zhao, X.; Wang, L. Atmospheric Oxidation Mechanism of Furfural Initiated by Hydroxyl Radicals. J. Phys. Chem. A 2017, 121, 3247-3253. [CrossRef]

11. Andreae, M.O.; Crutzen, P.J. Atmospheric Aerosols: Biogeochemical Sources and Role in Atmospheric Chemistry. Science 1997, 276, 1052-1058. [CrossRef]

12. Haywood, J.; Boucher, O. Estimates of the direct and indirect radiative forcing due to tropospheric aerosols: A review. Rev. Geophys. 2000, 38, 513-543. [CrossRef]

13. Kanakidou, M.; Seinfeld, J.H.; Pandis, S.N.; Barnes, I.; Dentener, F.J.; Facchini, M.C.; Van Dingenen, R.; Ervens, B.; Nenes, A.; Nielsen, C.J.; et al. Organic aerosol and global climate modelling: A review. Atmos. Chem. Phys. Discuss. 2005, 5, 1053-1123. [CrossRef]

14. Taylor, W.D.; Allston, T.D.; Moscato, M.J.; Fazekas, G.B.; Kozlowski, R.; Takacs, G.A. Atmospheric photodissociation lifetimes for nitromethane, methyl nitrite, and methyl nitrate. Int. J. Chem. Kinet. 1980, 12, 231-240. [CrossRef]

15. Schott, G.; Davidson, N. Shock Waves in Chemical Kinetics: The Decomposition of N2O5at High Temperatures. J. Am. Chem. Soc. 1958, 80, 1841-1853. [CrossRef]

16. Colmenar, I.; Cabañas, B.; Martínez, E.; Salgado, M.S.; Martín, P. Atmospheric reactions between E,E-2,4-hexadienal and $\mathrm{OH}, \mathrm{NO}_{3}$ radicals and $\mathrm{Cl}$ atoms. Atmos. Environ. 2014, 99, 159-167. [CrossRef]

17. Villanueva, F.; Barnes, I.; Monedero, E.; Salgado, S.; Gómez, M.V.; Martín, P.; Villalba, M.E.M. Primary product distribution from the $\mathrm{Cl}$-atom initiated atmospheric degradation of furan: Environmental implications. Atmos. Environ. 2007, 41, 8796-8810. [CrossRef]

18. Grainne, M.C.; Thüner, L.; Wenger, J.C.; Shallcross, D.E. Kinetics of the gas-phase reactions of $\mathrm{OH}$ and $\mathrm{NO}_{3}$ radicals with aromatic aldehydes. J. Photochem. Photobiol. A Chem. 2005, 176, 172-182. [CrossRef]

19. Bierbach, A.; Bröske, R.; Klotz, B.; Kurtenbach, R.; Libuda, G.; Maurer, T.; Nozière, B.; Patroescu, I.V.; Puhto, K.; Ruppert, L.; et al. FTIR Absortionskoefizienten Organischer und Anorganischer Verbindungen in der Gasphase bei 298 K und 760 Torr; Universität Wuppertal: Wuppertal, Germany, 1997.

20. Back, R.A.; Parsons, J.M. The thermal and photochemical decomposition of maleic anhydride in the gas phase. Can. J. Chem. 1981, 59, 1342-1346. [CrossRef]

21. Lauraguais, A.; Coeur-Tourneur, C.; Cassez, A.; Seydi, A. Rate constant and secondary organic aerosol yields for the gas-phase reaction of hydroxyl radicals with syringol (2,6-dimethoxyphenol). Atmos. Environ. 2012, 55, 43-48. [CrossRef]

22. Kroll, J.H.; Ng, N.L.; Murphy, S.M.; Flagan, R.C.; Seinfeld, J.H. Secondary Organic Aerosol Formation from Isoprene Photooxidation. Environ. Sci. Technol. 2006, 40, 1869-1877. [CrossRef] [PubMed]

23. Chan, A.W.H.; Chan, M.N.; Surratt, J.D.; Chhabra, P.S.; Loza, C.L.; Crounse, J.D.; Yee, L.D.; Flagan, R.C.; Wennberg, P.O.; Seinfeld, J.H. Role of aldehyde chemistry and NOx concentrations in secondary organic aerosol formation. Atmos. Chem. Phys. Discuss. 2010, 10, 7169-7188. [CrossRef]

24. Krechmer, J.E.; Coggon, M.M.; Massoli, P.; Nguyen, T.B.; Crounse, J.D.; Hu, W.; Day, D.A.; Tyndall, G.S.; Henze, D.K.; Rivera-Rios, J.C.; et al. Formation of Low Volatility Organic Compounds and Secondary Organic Aerosol from Isoprene Hydroxyhydroperoxide Low-NO Oxidation. Environ. Sci. Technol. 2015, 49, 10330-10339. [CrossRef] [PubMed]

(C) 2020 by the authors. Licensee MDPI, Basel, Switzerland. This article is an open access article distributed under the terms and conditions of the Creative Commons Attribution (CC BY) license (http://creativecommons.org/licenses/by/4.0/). 